\title{
Interaction between genetic and epigenetic variation defines gene expression patterns at the asthma-associated locus 17q12-q21 in lymphoblastoid cell lines
}

\author{
Soizik Berlivet $\cdot$ Sanny Moussette $\cdot$ Manon Ouimet $\cdot$ Dominique J. Verlaan $\cdot$ \\ Vonda Koka • Abeer Al Tuwaijri · Tony Kwan • Daniel Sinnett · \\ Tomi Pastinen • Anna K. Naumova
}

Received: 25 October 2011 / Accepted: 9 January 2012 / Published online: 24 January 2012

(C) The Author(s) 2012. This article is published with open access at Springerlink.com

\begin{abstract}
Phenotypic variation results from variation in gene expression, which is modulated by genetic and/or epigenetic factors. To understand the molecular basis of human disease, interaction between genetic and epigenetic factors needs to be taken into account. The asthma-associated region 17q12-q21 harbors three genes, the zona pellucida binding protein 2 (ZPBP2), gasdermin $\mathrm{B}(G S D M B)$ and ORM1-like 3 (ORMDL3), that show allele-specific differences in expression levels in lymphoblastoid cell lines (LCLs) and CD4+ T cells. Here, we report a molecular
\end{abstract}

Electronic supplementary material The online version of this article (doi:10.1007/s00439-012-1142-x) contains supplementary material, which is available to authorized users.

S. Berlivet · S. Moussette $\cdot$ A. K. Naumova $(\bowtie)$

Department of Obstetrics and Gynecology,

McGill University, Montreal, QC, Canada

e-mail: anna.naoumova@mcgill.ca

S. Moussette · A. K. Naumova

The Research Institute of the McGill University Health Centre,

Montreal, QC, Canada

M. Ouimet $\cdot$ D. Sinnett

Research Center, CHU Sainte-Justine, Montreal, QC, Canada

D. J. Verlaan · V. Koka · T. Kwan · T. Pastinen

McGill University and Genome Quebec Innovation Centre,

Montreal, QC, Canada

A. Al Tuwaijri · T. Pastinen · A. K. Naumova

Department of Human Genetics, McGill University,

Montreal, QC, Canada

D. Sinnett

Department of Pediatrics, University of Montreal,

Montreal, QC, Canada dissection of allele-specific transcriptional regulation of the genes within the chromosomal region 17q12-q21 combining in vitro transfection, formaldehyde-assisted isolation of regulatory elements, chromatin immunoprecipitation and DNA methylation assays in LCLs. We found that a single nucleotide polymorphism rs4795397 influences the activity of $Z P B P 2$ promoter in vitro in an allele-dependent fashion, and also leads to nucleosome repositioning on the asthmaassociated allele. However, variable methylation of exon 1 of $Z P B P 2$ masks the strong genetic effect on $Z P B P 2$ promoter activity in LCLs. In contrast, the ORMDL3 promoter is fully unmethylated, which allows detection of genetic effects on its transcription. We conclude that the cis-regulatory effects on 17q12-q21 gene expression result from interaction between several regulatory polymorphisms and epigenetic factors within the cis-regulatory haplotype region.

\section{Introduction}

Phenotypic variation is largely dependent on variation in gene expression levels. To identify the genetic determinants of phenotypic variation (including complex disease) in the human population, several genome-wide studies of genetically defined differences in gene expression levels succeeded to map cis-regulatory polymorphisms for a proportion of genes with variable expression (Dixon et al. 2007; Ge et al. 2009; Goring et al. 2007; Pastinen et al. 2004; Verlaan et al. 2009b; Yan et al. 2002). In a number of regions, including the chromosomal region 17q12-q21, genetic cis-effects act over several neighboring genes $(\mathrm{Ge}$ et al. 2009; Lluis et al. 2011; Verlaan et al. 2009a, b). Genome-wide association studies (GWAS) of gene expression in LCLs (Verlaan et al. 2009a, b) detected allele-specific 
differences in the expression of three genes: zona pellucida binding protein 2 (ZPBP2), ORM1-like 3 (S. cerevisiae) (ORMDL3) and gasdermin B (GSDMB) located in 17q12-q21 (Fig. 1a). This genomic interval is also associated with predisposition to early onset asthma, Crohn disease, ulcerative colitis and rheumatoid arthritis (Anderson et al. 2011; Barrett et al. 2008; Moffatt et al. 2007, 2011; Stahl et al. 2010). A cis-regulatory region responsible for the observed allele-specific differences in expression in CEPH LCLs has been mapped to a $160-\mathrm{kb}$ long genomic interval that overlaps IKAROS family zinc finger 3 (Aiolos) (IKZF3), ZPBP2, GSDMB and ORMDL3 (Verlaan et al. 2009a) (Fig. 1a). Two common cis-regulatory haplotypes, the asthma-associated HapA and the non-asthma associated HapB (also harboring the risk alleles for Crohn disease, ulcerative colitis and rheumatoid arthritis) have been delineated (Verlaan et al. 2009a) (Fig. 1a, b). HapA is associated with higher expression of ORMDL3 and GSDMB and lower expression of $Z P B P 2$ whereas HapB is associated with an opposite pattern of gene expression, i.e. lower expression of $O R M D L 3$ and $G S D M B$ and higher expression of $Z P B P 2$. Expression of $I K Z F 3$ is similar for both haplotypes (Verlaan et al. 2009a). Elucidation of the regulatory mechanism that underlies the effect of common polymorphisms on gene regulation is essential for the understanding of pathogenesis of asthma and other autoimmune diseases; therefore a search for functional cisregulatory polymorphisms was undertaken. This search identified SNP rs12936231 that modifies a CTCF-binding site and influences nucleosome occupancy (Verlaan et al. 2009a). Suggestive functional results were found for several other SNPs from the candidate regulatory region. To further elucidate the transcriptional control of this asthma-associated locus, we focused on the interaction between genetic and epigenetic factors in the promoter regions of the three genes whose expression depends upon the cis-regulatory haplotype.

\section{Materials and Methods}

Cell culture of lymphoblastoid cell lines

HapMap LCLs were purchased from the Coriell Cell Repositories (Camden, NJ) and grown in T75 flasks in $1 \times$ RPMI 1640 Media (Invitrogen, Carlsbad, CA) (with $2 \mathrm{mM}$ L-glutamine, $15 \%$ fetal bovine serum and $1 \%$ penicillin/ streptomycin) at $37^{\circ} \mathrm{C}$ with $5 \% \mathrm{CO}_{2}$. For formaldehydeassisted isolation of regulatory elements (FAIRE) and chromatin immunoprecipitation (ChIP) assays, LCLs were grown to $90 \%$ confluence. Two independent cultures of cells were used for the FAIRE assay (input and FAIRE-treated cells).
Transient transfection assays

To test for allelic activity, haplotype-specific constructs were subcloned into a pGL3 vector containing a firefly luciferase reporter gene either without a promoter or with an SV40 promoter (Promega, Madison, WI) using a previously published method (Belanger et al. 2005). All constructs were tested in five different human immortalized cell lines: cervical cancer (HeLa), choriocarcinoma (Jeg3), hepatocellular liver carcinoma (HepG2), osteosarcoma (MG-63) and CD4+ T-cell lymphoblast-like (Jurkat). These cell lines were transfected using lipofectamine ${ }^{\mathrm{TM}} 2000$ according to the manufacturer's protocol (Invitrogen, Carlsbad, CA). To control for transfection efficiency, the measurement of the firefly luciferase was normalized to the measurement of the Renilla luciferase. Experiments were performed in quadruplicate, the activities of the two luciferases were measured $24 \mathrm{~h}$ after transfection and allelic haplotypes for each SNP were compared. Statistical significance ( $P$ value) was determined using an unpaired Student's $t$ test.

Formaldehyde-assisted isolation of regulatory elements (FAIRE) assays

The FAIRE procedure was performed as described (Giresi et al. 2007) with some modifications (Verlaan et al. 2009a). To test for FAIRE enrichment of specific SNP regions, 200-400 ng of DNA was amplified by PCR. For SNP regions that showed FAIRE enrichment, normalized Sanger sequencing was done. FAIRE-treated DNA samples were compared to the input DNA samples and normalized allelic ratios were calculated. The primers used for FAIRE analysis are listed in supplementary Table $2 \mathrm{~S}$.

Chromatin immunoprecipitation (ChIP) assays

ChIP assays were performed as described in (Verlaan et al. 2009a). The following antibodies were used for ChIP assays: anti-histone H3K9Ac (06-942), anti-histone H3K27me3 (07-449); anti-C/EBP alpha (04-1104), anti-RNA Pol II (17-672) and anti-CTCF (07-729) (Millipore, Temecula, $\mathrm{CA})$; anti-NF $\kappa \mathrm{B}$ p65 (C-20), anti-YY1 (H-10) and antiEP300 (C-20) (Santa Cruz Biotechnology, Inc.). Genomic regions known to be enriched for these proteins were used as positive controls [supplementary Table $2 \mathrm{~S}$ and (Verlaan et al. 2009a)]. Promoter regions of the tumor necrosis factor receptor superfamily, member $1 \mathrm{~A}$ (TNFRSF1A) and intercellular adhesion molecule 1 (ICAMI) genes that were used as positive controls for C/EBP alpha did not show enrichment, possibly due to antibody specificity. Primers used for quantitative PCR analysis or Sanger sequencing following ChIP assays are listed in the supplementary Table 2S. 
a
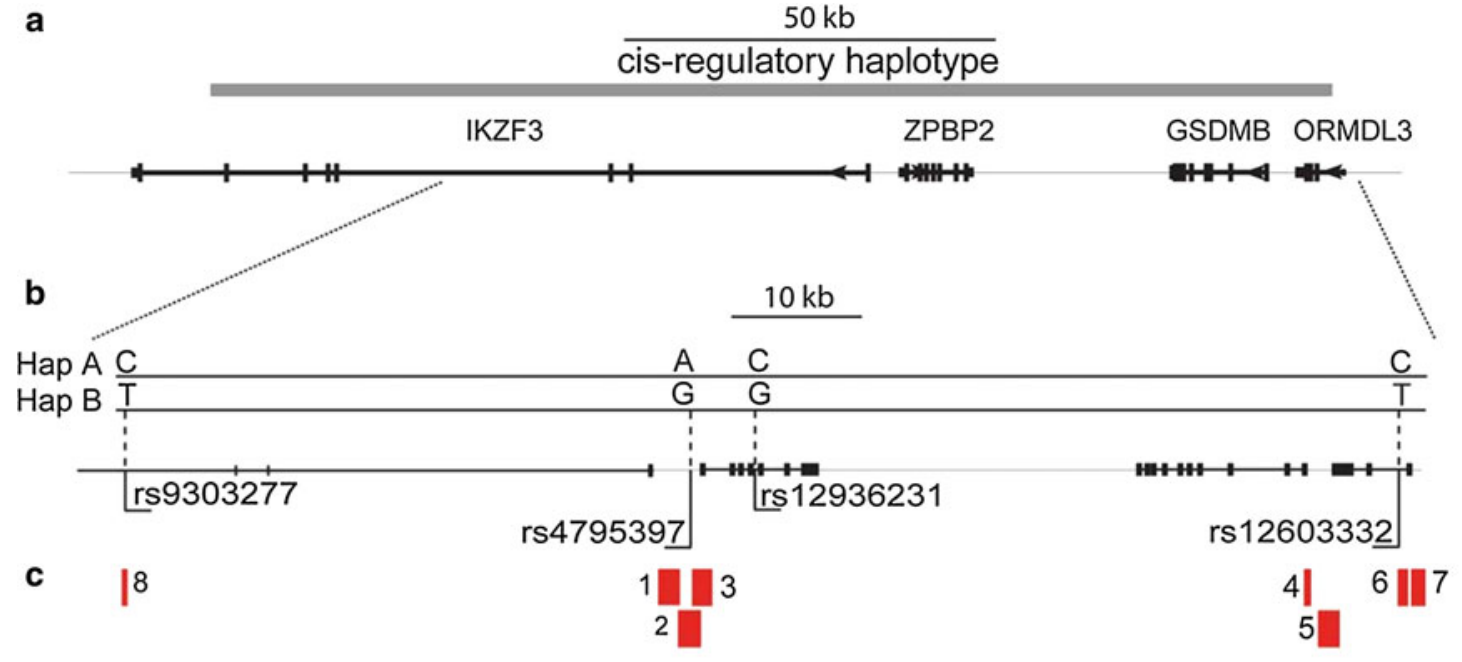

d

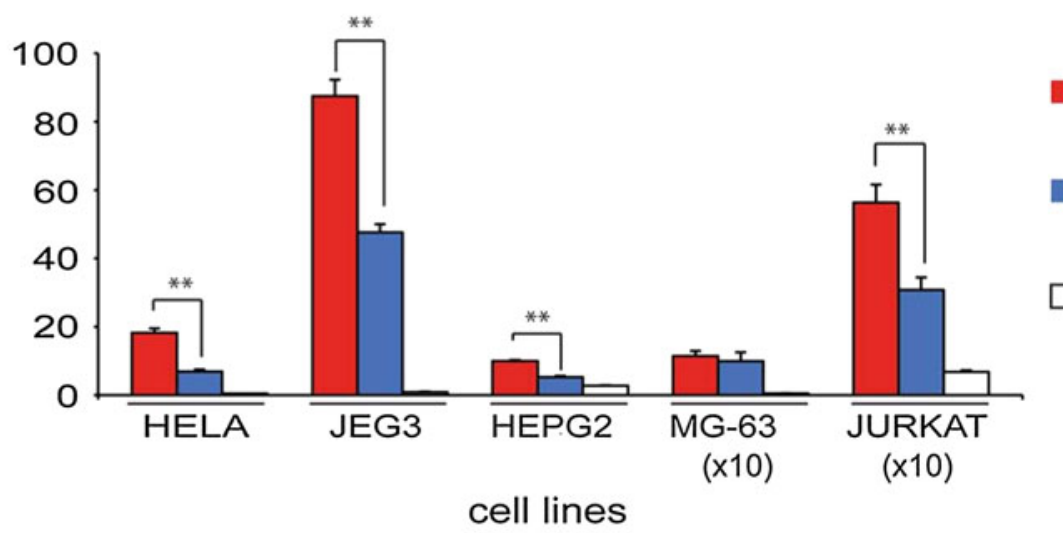

HapA

HapB

pGL3Basic

e

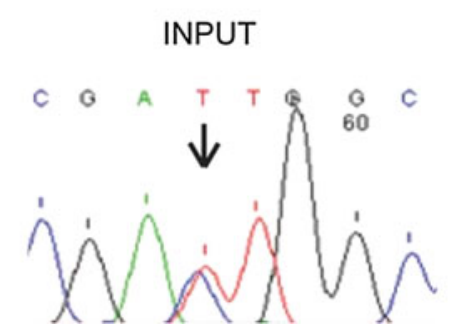

Fig. 1 Functional analysis of the cis-regulatory region in 17q12-q21. a Genomic position of the cis-regulatory haplotype (hg18, chr17: $35,179,985-35,339,296)$ associated with allelic expression of ORMDL3 and GSDMB (Verlaan et al. 2009a). b Positions of the common SNPs that form the cis-regulatory haplotype. For each SNP, the genotype associated with the haplotype A and B (HapA and HapB, respectively) is indicated on the top. HapA harbors the asthma-associated alleles and HapB harbors the non-asthma associated alleles. $\mathbf{c}$ Relative positions of the regions analyzed for in vitro promoter or enhancer activity.

Sodium bisulfite sequencing methylation analysis

To establish the methylation patterns of regulatory regions, $0.5-2 \mu \mathrm{g}$ of DNA was treated with sodium bisulfite as previously described (Clark et al. 1994) with modifications (Saferali et al. 2010). Assays were designed for each of the regions of interest. Nested PCR was performed for each of the loci. PCR products were purified

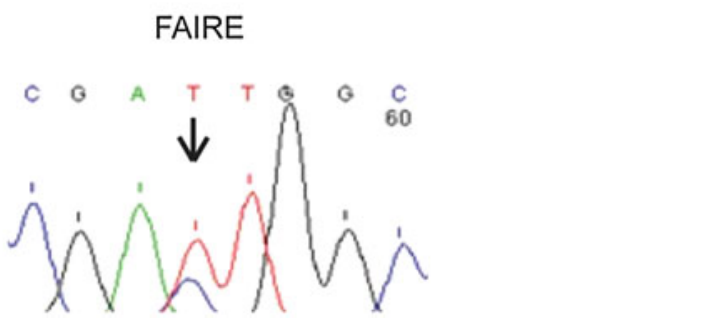

d Allelic differences in $Z P B P 2$ promoter activity in vitro. The $Z P B P 2$ promoter (region 2) that contains the rs4795397-A allele shows stronger promoter activity in vitro. A pGL3Basic plasmid has been used as negative control. The $Y$-axis indicates fold increase in transcription. Statistically significant allelic differences are indicated by asterisks; e allele-specific nucleosome occupancy detected by FAIRE at the rs4795397 region. Chromatograms for the input and FAIRE-enriched samples are shown. The position of the SNP rs4795397 is indicated by an arrow

using the MinElute gel extraction kit (Qiagen, Hilden, Germany) and cloned using the TOPO TA cloning kit (Invitrogen, Carlsbad, CA). The sequencing was done by the sequencing platform of the McGill University and Genome Quebec Innovation Centre. On average, 20 clones per sample were sequenced. Characteristics of regions, primers and PCR conditions are summarized in Supplementary Table 1S. 


\section{Results}

Allelic differences in $Z P B P 2$ and $O R M D L 3$ promoter activity

To determine to what extent allelic differences in gene expression levels in the $17 \mathrm{q} 12-\mathrm{q} 21$ region were defined by genetic polymorphisms within gene promoters, the activity of annotated promoter regions of $Z P B P 2, G S D M B$ and $O R M D L 3$ was tested in in vitro transfection assays in five different cell types (Table 1; Fig. 1c). The annotated $G S D M B$ promoter region did not show significant promoter activity in any of the cell types tested (region 4, Table 1). Two putative $O R M D L 3$ promoter regions were tested. The promoter region for the major ORMDL3 isoform showed high promoter activity in all tested cell lines with no allelic effect (region 7, Table 1), whereas the putative promoter region for the minor isoform of ORMDL3 (region 6) that included SNP rs12603332 (C/T) showed promoter activity in MG63 cells with a strong allelic effect. The construct that carried the haplotype HapA-associated rs12603332-C allele had higher promoter activity $(P<0.01$, Student's $t$ test) (Table 1). However, exome sequencing data suggest that this promoter is not active in LCLs (Kwan et al. 2009). The construct including both promoters maintained high promoter activity; however, the allelic effect was lost (Table 1).

In the $Z P B P 2$ promoter region, the construct that carried the HapA-associated rs4795397-A allele in HeLa, Jeg3, HepG2 and Jurkat cells showed higher promoter activity ( $P<0.01$, Student's $t$ test) (Fig. $1 \mathrm{~d}$ and region 2; Table 1$)$. A partially overlapping construct that contained the transcriptional start site, exons 1 and 2 of $Z P B P 2$ was active only in JEG3 cells and showed a significant allelic effect $(P<0.05$, Student's $t$ test) (region 3, Table 1).

In conclusion, the asthma-associated HapA haplotype variants of the $Z P B P 2$ promoter region and the putative promoter for the minor ORMDL3 isoform had higher in vitro promoter activity compared to the variants associated with the HapB haplotype.

\section{Allele-specific regulatory elements}

Cis-regulatory allelic effects may arise from allele-specific differences in transcription factor binding and enhancer activity (Agueda et al. 2011; Bickel et al. 2011; Colombo et al. 2011; Harmon et al. 2010; Mertens et al. 2010). Transcription factor binding to a regulatory DNA element usually results in repositioning of nucleosomes. Allelic effects of putative regulatory SNPs on nucleosome positioning were explored using the FAIRE assay that identifies DNA regions with reduced nucleosome occupancy, i.e. regions potentially associated with transcription factors (Giresi

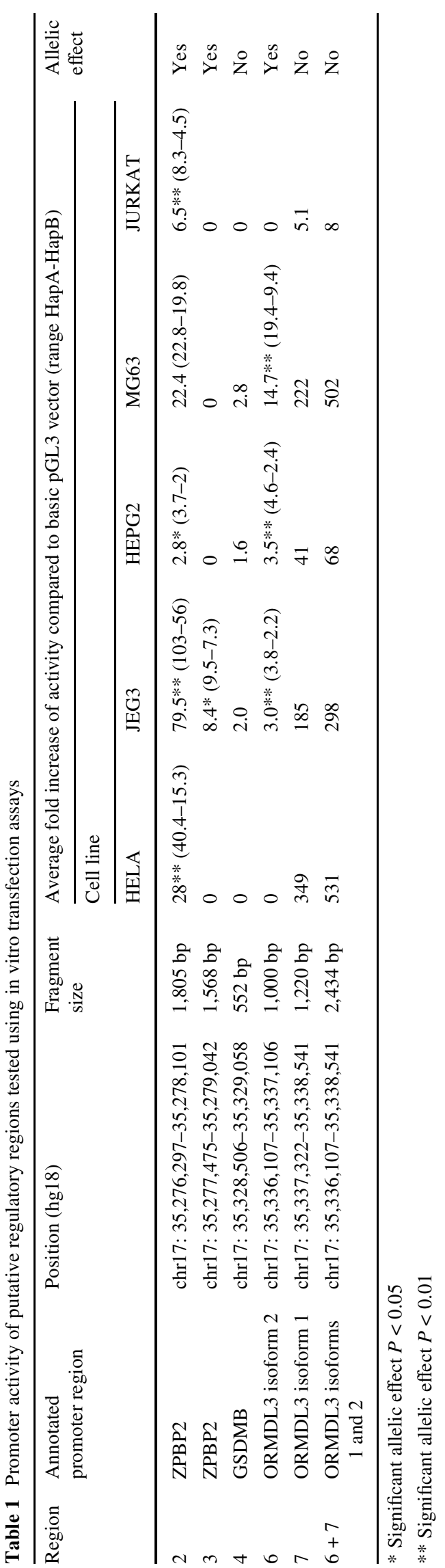


et al. 2007). Two of the 22 tested SNP regions, rs 12936231 and rs4795397, showed both an overall FAIRE enrichment and allelic differences in nucleosome occupancy (Verlaan et al. 2009a). The effect of SNP rs12936231 on nucleosome occupancy and CTCF-binding has been described in detail elsewhere (Verlaan et al. 2009a). The SNP rs4795397 residing in the proximal promoter region of $Z P B P 2$ also influenced FAIRE enrichment in five of six heterozygous LCLs tested. The rs4795397 A-allele had about twofold higher FAIRE enrichment than the rs4795397-G allele (Fig. 1e). The A-allele is part of the asthma-associated haplotype HapA and is associated with lower expression level of $Z P B P 2$ in CEU LCLs. However, it shows higher promoter activity in vitro (Fig. 1d). Hence, overall our data indicate that the allele that confers higher promoter activity in in vitro gene reporter assays and is associated with reduced nucleosome occupancy, i.e. with transcription factors in vivo, surprisingly, is the same allele that is associated with lower expression levels of the ZPBP2 gene.

The Encode ChIP-sequencing results show enrichment of at least twelve transcription factors within the rs4795397 region (Myers et al. 2011; Raney et al. 2011). These include the nuclear factor of kappa light polypeptide gene enhancer in B-cells $1(\mathrm{NF} \kappa \mathrm{B})$ p65 subunit, which is a central player in inflammation and immunity, RNA polymerase II (RNA POL II), and the transcriptional co-activator E1A binding protein p300 (EP300) (supplementary Fig. 1S). Analysis of the DNA sequence of the rs4795397 region (Transcription Element Search System database, http:// www.cbil.upenn.edu/cgi-bin/tess) predicts binding sites for Yin and Yang 1 (YY1) and the CCAAT/enhancer binding protein $(\mathrm{C} / \mathrm{EBP})$ alpha transcription factors that overlap the SNP. To determine if SNP rs4795397 influences transcription factor binding in vivo, enrichment with $\mathrm{NF} \kappa \mathrm{B}, \mathrm{EP} 300$, YY1, C/EBP alpha, RNA POL II and insulator protein CTCF was tested in LCLs that were homozygous for either the rs4795397-A or the rs4795397-G allele using ChIP. The region was enriched with $\mathrm{NF} \kappa \mathrm{B}, \mathrm{YY} 1, \mathrm{EP} 300$ and RNA POL II (Table 2). High inter-individual variation between cell lines with respect to transcription factor enrichment and no statistically significant effect of the genotype were observed. We tested the allelic effect on $\mathrm{NF} \kappa \mathrm{B}$ alpha and RNA POL II enrichment using ChIP followed by Sanger sequencing in two heterozygous cell lines. No significant allelic differences in enrichment were detected (Table 2). We conclude that NF $\kappa$ B, RNA POL II, YY1 and EP300 bind both alleles in the rs4795397 region.

The rs4795397 region was also highly enriched for the active histone mark $\mathrm{H} 3 \mathrm{Ac}$, and showed low enrichment for the inactive histone mark $\mathrm{H} 3 \mathrm{~K} 27 \mathrm{me} 3$ that were also independent from genotype (Table 2). C/EBP alpha ChIP results were not conclusive as enrichment was not detected in any of the regions tested including positive controls, perhaps due to antibody specificity.

The transcriptional control of genes within the 17q12-q21 chromosomal region is poorly understood and enhancers that regulate $O R M D L 3$ and $G S D M B$ expression have not been yet identified. To locate putative enhancers, we searched the publically available data [UCSC database (Raney et al. 2011; Myers et al. 2011)] for genomic regions that were enriched for enhancer-specific epigenetic marks e.g. histones H3K4me1 and H3K27Ac; and/or the transcriptional co-activator E1A binding protein p300 (EP300) (supplementary Fig. 1S). These regions were tested for in vitro enhancer activity (Fig. 1; Table 3 and supplementary Fig. 1S). The candidate enhancer region overlapping with the $5^{\prime}$ region of the $Z P B P 2$ gene was too large and had to be tested as 3 separate overlapping constructs (regions 1-3 in Table 3). Enhancer activity was detected for the $Z P B P 2$ promoter region (region 2) in Jeg3 and MG63 cells, for region 1 in Jeg3 cells; for the ORMDL3 promoter (region 6) and $3^{\prime}$ regions in MG63 cells; for the ORMDL3 promoter (region 7) in all cell lines except Jurkat cells (Table 3). Significant allelic effects were observed for regions 2 and 3 (Table 3 ).

Collectively, our data demonstrate that the common SNP rs4795397 is a regulatory polymorphism that affects promoter activity, nucleosome positioning and is part of an enhancer region.
Table 2 Enrichment of the rs4795397 region chromatin with transcription factors in LCLs

Standard deviation is given if three of more LCLs were tested $n t$ not tested

\begin{tabular}{lllll}
\hline ChIP & Enrichment & & & $\begin{array}{l}\text { Allelic effect tested } \\
\text { by Sanger sequencing }\end{array}$ \\
\cline { 2 - 4 } & $\begin{array}{l}\text { All genotypes } \\
\text { (number of LCLs } \\
\text { tested) }\end{array}$ & $\begin{array}{l}\text { Homozygous } \\
\text { HapA (number } \\
\text { of LCLs tested) }\end{array}$ & $\begin{array}{l}\text { Homozygous } \\
\text { HapB (number } \\
\text { of LCLs tested) }\end{array}$ & $\begin{array}{l}\text { heterozygous LCLs } \\
\text { (number of LCLs tested) }\end{array}$ \\
\hline NFkB & $2.06 \pm 0.60(8)$ & $2.42 \pm 0.73(3)$ & $1.57 \pm 0.14(3)$ & Absent (2) \\
CTCF & $1.06 \pm 0.46(8)$ & $1.11 \pm 0.51(4)$ & $1.01 \pm 0.49(4)$ & $\mathrm{nt}$ \\
YY1 & $3.36 \pm 1.57(5)$ & $3.58 \pm 2.16(3)$ & $3.03(2)$ & $\mathrm{nt}$ \\
EP300 & $2.63 \pm 0.91(4)$ & $2.86(2)$ & $2.39(2)$ & $\mathrm{nt}$ \\
RNA POL II & $6.75(2)$ & $\mathrm{nt}$ & $\mathrm{nt}$ & $\mathrm{Absent} \mathrm{(2)}$ \\
Histone H3K9Ac & $57.41 \pm 20.95(4)$ & $50.44(2)$ & $64.27(2)$ & $\mathrm{nt}$ \\
Histone H3K27me3 & $1.98 \pm 0.20(4)$ & $1.92(2)$ & $2.04(2)$ & $\mathrm{nt}$ \\
\hline
\end{tabular}




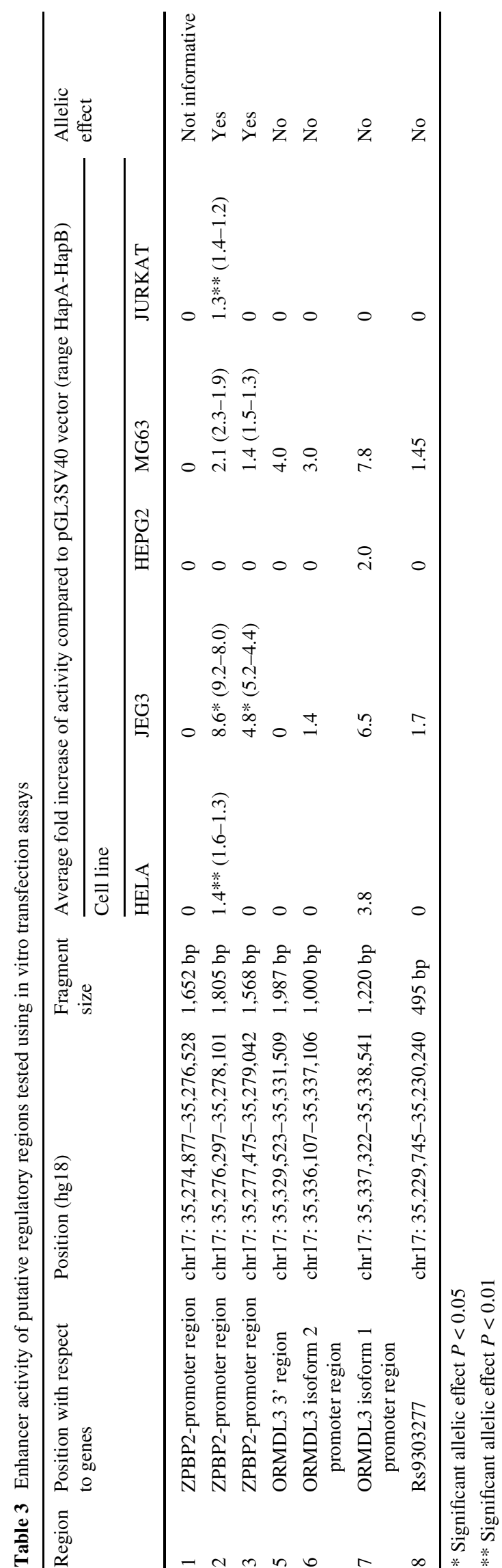

DNA methylation of promoter regions

Monoallelic expression of certain X-linked and imprinted genes results from allelic differences in promoter methylation. To determine if promoter methylation had an effect on the expression of the 17q12-q21 genes in LCLs, methylation profiles of the annotated IKZF3, ZPBP2, GSDMB, $O R M D L 3$ and GSDMA promoters and first exons were determined (Fig. 2). The ORMDL3 and IKZF3 promoters were unmethylated in all tested cell lines independent from their genotypes (supplementary Figs. 2S, 3S). The annotated $G S D M B$ promoter and exon 1 of isoform 2 were highly methylated in all genotypes [11 LCLs were tested, (supplementary Fig. 4S)] suggesting that transcription of the major annotated isoform 2 of GSDMB was suppressed in LCLs, which is in agreement with the exome sequencing data (Fig. 2a). It is worth noting, however, that the haplotype HapA contains polymorphisms that abolish three out of seven CG sites in the annotated GSDMB promoter. Moreover, this region had slightly lower mean methylation levels in LCLs that were homozygous for the HapA haplotype ( $n=3$; mean methylation level $79.7 \%)$ compared to LCLs that were heterozygous $(n=4$, mean methylation level $95.7 \%$ ) or homozygous for the HapB haplotype $(n=4$, mean methylation level $95.6 \%)$. For all 11 LCLs, the methylation level of the GSDMB promoter and exon 1 was inversely correlated with RNA abundance (Pearson's correlation coefficient $r=-0.63, \alpha=0.05$ ).

In contrast to ORMDL3 and GSDMB promoters, the $Z P B P 2$ promoter and exon 1 region showed highly variable DNA methylation patterns both within and between cell lines (Fig. 3a). Sixteen LCLs were tested. The ZPBP2 promoter was highly methylated in cell lines homozygous for the asthma-associated HapA haplotype $(n=5)$ and in heterozygous cell lines $(n=6)$, but had lower methylation levels in cell lines that were homozygous for the non-asthma associated HapB haplotype $(n=5)$. To determine if ZPBP2 methylation depended upon the parental origin of the allele, we compared the methylation profiles of maternal and paternal alleles in two LCL DNA samples, NA10838 and NA12878. No significant parental origin effect was detected.

Comparison of $Z P B P 2$ promoter and exon 1 methylation and expression levels showed a strong inverse correlation between methylation of exon 1 and ZPBP2 RNA levels (Pearson's correlation coefficient $R=-0.88, \alpha=0.05$ ) (Fig. 3b). Hence, methylation levels of ZPBP2 exon 1 influence $Z P B P 2$ RNA levels and explain the apparent contradiction between high in vitro activity and FAIRE enrichment of the $Z P B P 2$ promoter region and lower expression of $Z P B P 2$ in LCLs that carry the asthma-associated haplotype HapA.

GSDMA is not expressed in LCLs (Fig. 2a), therefore LCLs are not the appropriate model for testing genetic 


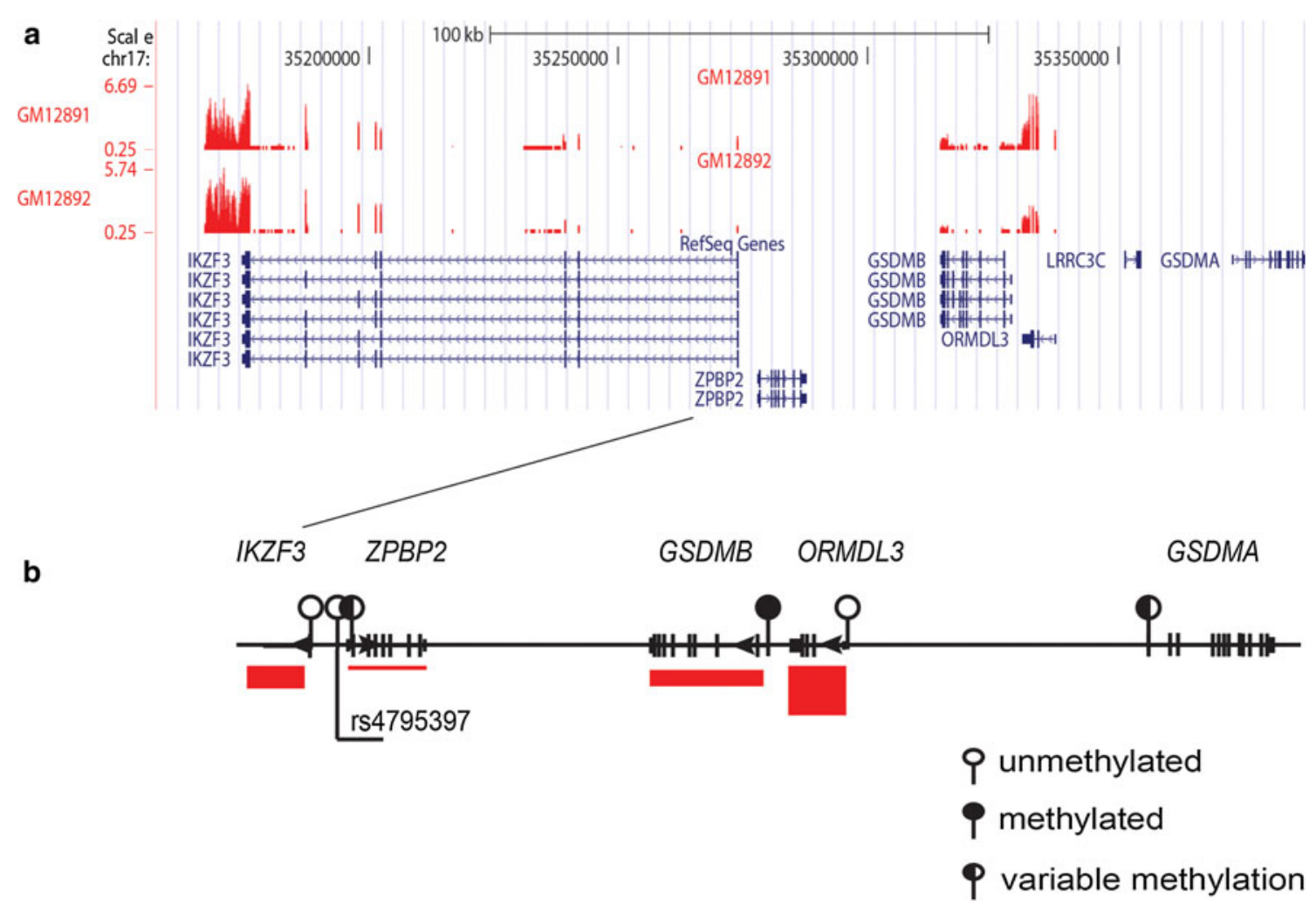

Fig. 2 Promoter methylation and gene expression patterns in the 17q12-q21 region. a Exome sequencing results for the region $17 \mathrm{q} 12$ q21 in two LCLs (GM12891 and GM12892). b Summary of DNA

cis-regulatory effects on its expression. However, increased expression of GSDMA was found in cord blood lymphocytes of individuals that carry the asthma-associated 17q12-q21 alleles (Lluis et al. 2011), suggesting that GSDMA cannot be excluded from the list of putative asthma genes. Hence, to obtain a complete picture of promoter methylation in the 17q12-q21 region we determined the methylation profile of the GSDMA promoter region in LCLs and found interindividual variation among LCLs with respect to methylation levels (supplementary Fig. 5S).

We also tested the methylation profile of the rs4795397 region for allelic effects and found that it was unmethylated independent of genotype (supplementary Fig. 6S).

Overall, the methylation profiles of promoter regions show a good correlation with the expression levels of respective genes, i.e. highly expressed transcripts such as $I K Z F 3$ and $O R M D L 3$ have completely unmethylated promoters, while genes with even partial promoter methylation show a considerably reduced transcriptional activity.

\section{Discussion}

The asthma-associated chromosomal region 17q12-q21 harbors several genes that show allelic differences in methylation results for the 17q12-21 region. Red rectangles below the diagram reflect the relative RNA abundance for genes in the region

expression in LCL. Our data suggest that allelic variation in expression arises from the interaction between several genetic polymorphisms and epigenetic factors. We have previously reported the effect of the common SNP rs12936231 on CTCF binding and nucleosome occupancy (Verlaan et al. 2009a). In the present study, we demonstrate that another common SNP, rs4795397 that is part of the cisregulatory haplotype and is located within the promoter region of the $Z P B P 2$ is a putative functional polymorphism that shows allele-specific nucleosome occupancy and in vitro promoter activity. The rs4795397 region is enriched with YY1 and co-activator protein EP300. YY1 and EP300 are known to form regulatory complexes that may repress (Galvin and Shi 1997; Lee et al. 1995) or activate (Mokrani et al. 2006, Baumeister et al. 2005) gene transcription in response to different stimuli including endoplasmic reticulum stress and viral infection. The rs4795397 region is enriched with the active histone mark H3K9Ac, but not the repressive chromatin mark $\mathrm{H} 3 \mathrm{~K} 27 \mathrm{me} 3$, an observation which is consistent with the histone acetyltransferase activity of EP300 (Ogryzko et al. 1996). Overall, the ChIP and FAIRE results indicate an active chromatin state at the rs4795397 region. Furthermore, our data show that although rs4795397 has a strong influence on promoter activity in vitro, in LCLs, its effect on $Z P B P 2$ transcription 

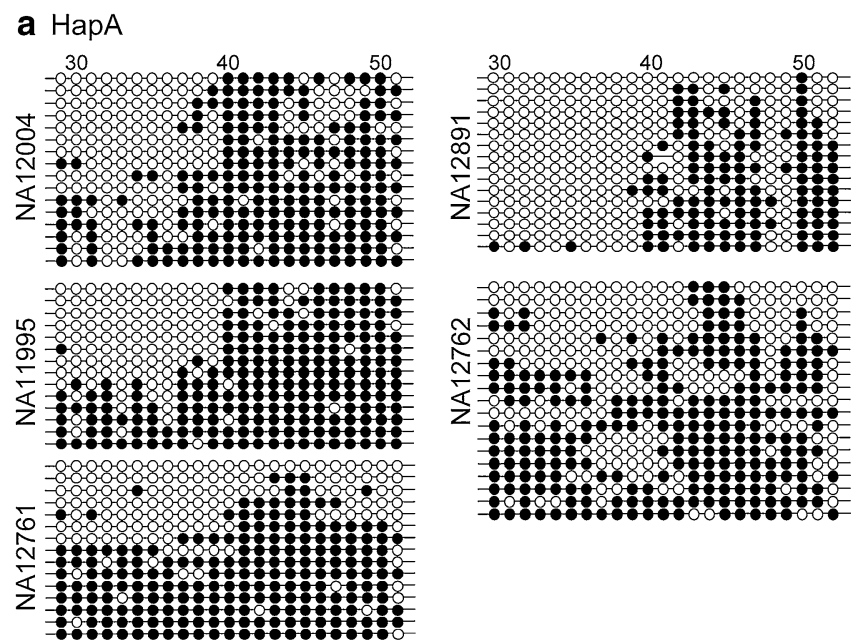

HapB
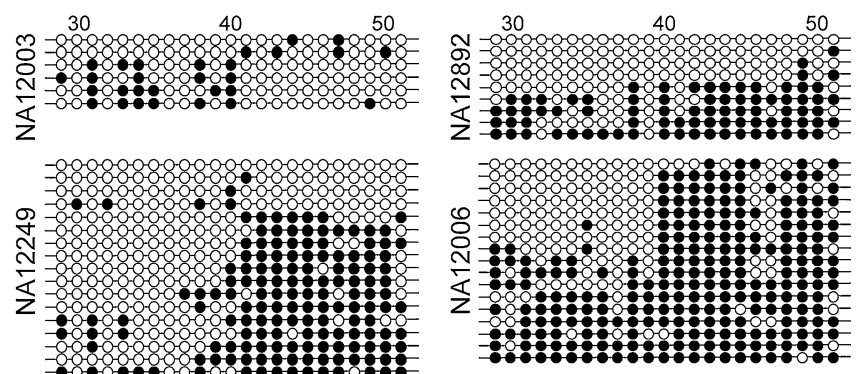

НарAB
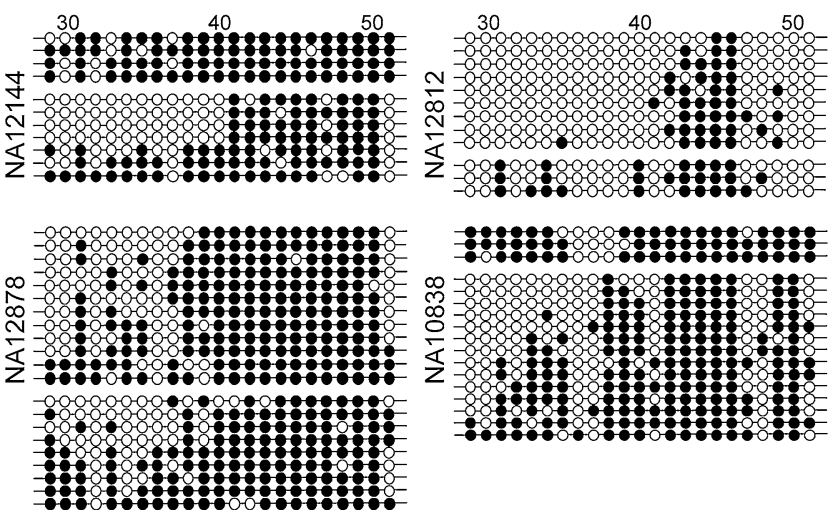

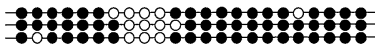

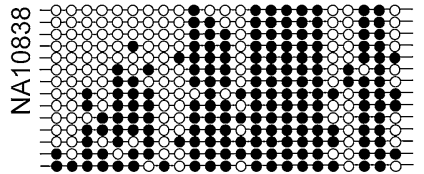

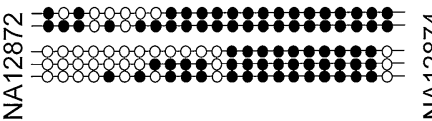

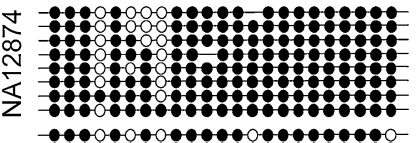

b

:88:

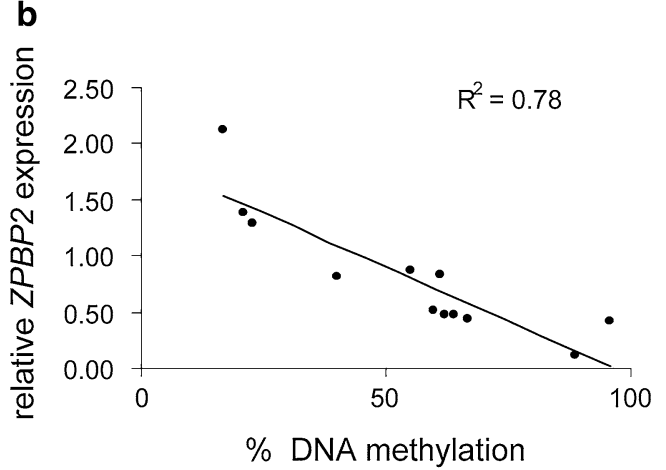

that are located within exon 1 of $Z P B P 2$ and have greater variability in DNA methylation are shown in the figure. b Negative correlation between $Z P B P 2$ exon 1 methylation and $Z P B P 2$ RNA abundance. $Z P B P 2$ expression was evaluated using real-time RT-PCR and normalized to the 18S RNA levels as described in (Verlaan et al. 2009a)

if the $Z P B P 2$ enhancer region exerts a long-range regulatory effect that extends beyond the $Z P B P 2$ gene and contributes to the allele-specific differences in the expression of $O R M D L 3$ and other genes in the region (Verlaan et al. 2009a).

The functional SNP rs4795397 is located within the promoter region of $Z P B P 2$, a gene whose importance for fertilization and male fertility has been demonstrated in both mice and humans (Lin et al. 2007; Redgrove et al. 2011). The rs4795397-A allele that boosts the ZPBP2 promoter activity in vitro is also part of the asthma-associated haplotype HapA. The exon 1 of $Z P B P 2$ is unmethylated in human sperm (S. Berlivet and A. Naumova, unpublished) and cannot block the allelic effect of rs4795397 on gene expression. Therefore, it is conceivable that spermatozoa from male carriers of the asthma-associated rs4795397-A allele have a higher supply of the ZPBP2 protein and potentially 
an increased fertilization capacity. This may provide a slight advantage at the population level and lead to an increased transmission of the asthma-associated haplotype from fathers to offspring.

Our results provide an example where inter-individual variation in DNA methylation acts as a modifier of genetic influences on gene expression and may interfere with genetic mapping of $c i s$-regulatory polymorphisms by attenuating the genetic effect on transcription and thereby the significance of genetic association results as in the case of the $Z P B P 2$ gene. Based on our results, we speculate that promoters and first exons of genes that show genetic ciseffect on expression levels with genome-wide statistical significance are likely not methylated at all, or else may have allele-specific methylation, where the low expressing allele would have high promoter methylation and vice versa.

DNA methylation of promoter and enhancer elements varies with cell type and/or developmental stage (Eckhardt et al. 2006; Ghosh et al. 2010). Therefore, cell-type specific DNA methylation patterns have to be taken into account in the search for candidate disease gene. Several lines of evidence point to ORMDL3 as the best $17 \mathrm{q} 21$ candidate causal gene for childhood asthma. Its expression levels show association with genotype in LCLs (Moffatt et al. 2007; Verlaan et al. 2009a, b), T lymphocytes (Murphy et al. 2010) and cord blood lymphocytes (Lluis et al. 2011). ORMDL3 is also expressed in bronchial epithelial cells and its RNA levels are slightly higher in asthmatic subjects compared to controls, whereas $G S D M B$ and $Z P B P 2$ are practically not expressed (Bochkov et al. 2010). Whether or not ORMDL3 is the causal gene responsible for predisposition to asthma remains to be addressed using other approaches. It is important to note, however, that while the current experimental evidence excludes IKZF3 (IKZF3 is not affected by the haplotype effect in LCLs or T lymphocytes), it is not sufficient for ruling out ZPBP2, GSDMB or GSDMA as contributors to predisposition to asthma. Allelic transcription of GSDMB in LCLs and T lymphocytes has been previously demonstrated (Verlaan et al. 2009a, b; Murphy et al. 2010). As for ZPBP2 and GSDMA, it is possible that in certain cell types their promoters may be unmethylated and their transcription may also depend on the haplotype. To exclude ZPBP2, GSDMB and GSDMA and narrow down the list of candidate genes for predisposition to asthma expression studies in cell types that are relevant for the etiology of asthma are necessary.

Acknowledgments This work was supported by funds from the Canadian Institutes of Health Research (CIHR) (AN). Research in the Department of Obstetrics and Gynecology, McGill University is supported by the Royal Victoria Hospital Research Foundation. AA is a recipient of the National Guard Health Affairs Saudi Arabia scholarship. DS holds the François-Karl Viau research Chair in Pediatric
Oncogenomics and is a scholar of the Fonds de la Recherche en Santé du Québec (FRSQ).

Conflict of interest The authors declare that they have no conflict of interests.

Open Access This article is distributed under the terms of the Creative Commons Attribution License which permits any use, distribution, and reproduction in any medium, provided the original author(s) and the source are credited.

\section{References}

Agueda L, Velazquez-Cruz R, Urreizti R, Yoskovitz G, Sarrion P, Jurado S, Guerri R, Garcia-Giralt N, Nogues X, Mellibovsky L, Diez-Perez A, Marie PJ, Balcells S, Grinberg D (2011) Functional relevance of the BMD-associated polymorphism rs312009: novel involvement of Runx2 in LRP5 transcriptional regulation. J Bone Miner Res 26:1133-1144

Anderson CA, Boucher G, Lees CW, Franke A, D'Amato M, Taylor KD, Lee JC, Goyette P, Imielinski M, Latiano A, Lagace C, Scott R, Amininejad L, Bumpstead S, Baidoo L, Baldassano RN, Barclay M, Bayless TM, Brand S, Buning C, Colombel JF, Denson LA, De Vos M, Dubinsky M, Edwards C, Ellinghaus D, Fehrmann RS, Floyd JA, Florin T, Franchimont D, Franke L, Georges M, Glas J, Glazer NL, Guthery SL, Haritunians T, Hayward NK, Hugot JP, Jobin G, Laukens D, Lawrance I, Lemann M, Levine A, Libioulle C, Louis E, McGovern DP, Milla M, Montgomery GW, Morley KI, Mowat C, Ng A, Newman W, Ophoff RA, Papi L, Palmieri O, Peyrin-Biroulet L, Panes J, Phillips A, Prescott NJ, Proctor DD, Roberts R, Russell R, Rutgeerts P, Sanderson J, Sans M, Schumm P, Seibold F, Sharma Y, Simms LA, Seielstad M, Steinhart AH, Targan SR, van den Berg LH, Vatn M, Verspaget $\mathrm{H}$, Walters T, Wijmenga C, Wilson DC, Westra HJ, Xavier RJ, Zhao ZZ, Ponsioen CY, Andersen V, Torkvist L, Gazouli M, Anagnou NP, Karlsen TH, Kupcinskas L, Sventoraityte J, Mansfield JC, Kugathasan S, Silverberg MS, Halfvarson J, Rotter JI, Mathew CG, Griffiths AM, Gearry R, Ahmad T, Brant SR, Chamaillard $\mathrm{M}$ et al (2011) Meta-analysis identifies 29 additional ulcerative colitis risk loci, increasing the number of confirmed associations to 47. Nat Genet 43:246-252

Barrett JC, Hansoul S, Nicolae DL, Cho JH, Duerr RH, Rioux JD, Brant SR, Silverberg MS, Taylor KD, Barmada MM, Bitton A, Dassopoulos T, Datta LW, Green T, Griffiths AM, Kistner EO, Murtha MT, Regueiro MD, Rotter JI, Schumm LP, Steinhart AH, Targan SR, Xavier RJ, Libioulle C, Sandor C, Lathrop M, Belaiche J, Dewit O, Gut I, Heath S, Laukens D, Mni M, Rutgeerts P, Van Gossum A, Zelenika D, Franchimont D, Hugot JP, de Vos M, Vermeire S, Louis E, Cardon LR, Anderson CA, Drummond H, Nimmo E, Ahmad T, Prescott NJ, Onnie CM, Fisher SA, Marchini J, Ghori J, Bumpstead S, Gwilliam R, Tremelling M, Deloukas P, Mansfield J, Jewell D, Satsangi J, Mathew CG, Parkes M, Georges M, Daly MJ (2008) Genome-wide association defines more than 30 distinct susceptibility loci for Crohn's disease. Nat Genet 40:955-962

Baumeister P, Luo S, Skarnes WC, Sui G, Seto E, Shi Y, Lee AS (2005) Endoplasmic reticulum stress induction of the Grp78/BiP promoter: activating mechanisms mediated by YY1 and its interactive chromatin modifiers. Mol Cell Biol 25:4529-4540

Belanger H, Beaulieu P, Moreau C, Labuda D, Hudson TJ, Sinnett D (2005) Functional promoter SNPs in cell cycle checkpoint genes. Hum Mol Genet 14:2641-2648

Bickel RD, Kopp A, Nuzhdin SV (2011) Composite effects of polymorphisms near multiple regulatory elements create a majoreffect QTL. PLoS Genet 7:e1001275 
Bochkov YA, Hanson KM, Keles S, Brockman-Schneider RA, Jarjour NN, Gern JE (2010) Rhinovirus-induced modulation of gene expression in bronchial epithelial cells from subjects with asthma. Mucosal Immunol 3:69-80

Clark SJ, Harrison J, Paul CL, Frommer M (1994) High sensitivity mapping of methylated cytosines. Nucleic Acids Res 22:29902997

Colombo F, Falvella FS, Galvan A, Frullanti E, Kunitoh H, Ushijima T, Dragani TA (2011) A 5'-region polymorphism modulates promoter activity of the tumor suppressor gene MFSD2A. Mol Cancer 10:81

Dixon AL, Liang L, Moffatt MF, Chen W, Heath S, Wong KC, Taylor J, Burnett E, Gut I, Farrall M, Lathrop GM, Abecasis GR, Cookson WO (2007) A genome-wide association study of global gene expression. Nat Genet 39:1202-1207

Eckhardt F, Lewin J, Cortese R, Rakyan VK, Attwood J, Burger M, Burton J, Cox TV, Davies R, Down TA, Haefliger C, Horton R, Howe K, Jackson DK, Kunde J, Koenig C, Liddle J, Niblett D, Otto T, Pettett R, Seemann S, Thompson C, West T, Rogers J, Olek A, Berlin K, Beck S (2006) DNA methylation profiling of human chromosomes 6, 20 and 22. Nat Genet 38:1378-1385

Ernst J, Kellis M (2010) Discovery and characterization of chromatin states for systematic annotation of the human genome. Nat Biotechnol 28:817-825

Ernst J, Kheradpour P, Mikkelsen TS, Shoresh N, Ward LD, Epstein CB, Zhang X, Wang L, Issner R, Coyne M, Ku M, Durham T, Kellis M, Bernstein BE (2010) Mapping and analysis of chromatin state dynamics in nine human cell types. Nature 473:43-49

Galvin KM, Shi Y (1997) Multiple mechanisms of transcriptional repression by YY1. Mol Cell Biol 17:3723-3732

Ge B, Pokholok DK, Kwan T, Grundberg E, Morcos L, Verlaan DJ, Le J, Koka V, Lam KC, Gagne V, Dias J, Hoberman R, Montpetit A, Joly MM, Harvey EJ, Sinnett D, Beaulieu P, Hamon R, Graziani A, Dewar K, Harmsen E, Majewski J, Goring HH, Naumova AK, Blanchette M, Gunderson KL, Pastinen T (2009) Global patterns of cis variation in human cells revealed by high-density allelic expression analysis. Nat Genet 41:1216-1222

Ghosh S, Yates AJ, Fruhwald MC, Miecznikowski JC, Plass C, Smiraglia D (2010) Tissue specific DNA methylation of CpG islands in normal human adult somatic tissues distinguishes neural from non-neural tissues. Epigenetics 5:527-538

Giresi PG, Kim J, McDaniell RM, Iyer VR, Lieb JD (2007) FAIRE (formaldehyde-assisted isolation of regulatory elements) isolates active regulatory elements from human chromatin. Genome Res $17: 877-885$

Goring HH, Curran JE, Johnson MP, Dyer TD, Charlesworth J, Cole SA, Jowett JB, Abraham LJ, Rainwater DL, Comuzzie AG, Mahaney MC, Almasy L, MacCluer JW, Kissebah AH, Collier GR, Moses EK, Blangero J (2007) Discovery of expression QTLs using large-scale transcriptional profiling in human lymphocytes. Nat Genet 39:1208-1216

Harmon BT, Devaney SA, Gordish-Dressman H, Reeves EK, Zhao P, Devaney JM, Hoffman EP (2010) Functional characterization of a haplotype in the AKT1 gene associated with glucose homeostasis and metabolic syndrome. Hum Genet 128:635-645

Kwan T, Grundberg E, Koka V, Ge B, Lam KC, Dias C, Kindmark A, Mallmin H, Ljunggren O, Rivadeneira F, Estrada K, van Meurs JB, Uitterlinden A, Karlsson M, Ohlsson C, Mellstrom D, Nilsson O, Pastinen T, Majewski J (2009) Tissue effect on genetic control of transcript isoform variation. PLoS Genet 5:e1000608

Lee JS, Galvin KM, See RH, Eckner R, Livingston D, Moran E, Shi Y (1995) Relief of YY1 transcriptional repression by adenovirus E1A is mediated by E1A-associated protein p300. Genes Dev 9:1188-1198

Lin YN, Roy A, Yan W, Burns KH, Matzuk MM (2007) Loss of zona pellucida binding proteins in the acrosomal matrix disrupts acro- some biogenesis and sperm morphogenesis. Mol Cell Biol 27:6794-6805

Lluis A, Schedel M, Liu J, Illi S, Depner M, von Mutius E, Kabesch M, Schaub B (2011) Asthma-associated polymorphisms in 17q21 influence cord blood ORMDL3 and GSDMA gene expression and IL-17 secretion. J Allergy Clin Immunol:3

Mertens J, Ramadori G, Mihm S (2010) Functional relevance of the IRF-1 promoter polymorphism rs2549009 on transcriptional activity in a native genomic environment. Hum Mol Genet 19: 4587-4594

Moffatt MF, Kabesch M, Liang L, Dixon AL, Strachan D, Heath S, Depner M, von Berg A, Bufe A, Rietschel E, Heinzmann A, Simma B, Frischer T, Willis-Owen SA, Wong KC, Illig T, Vogelberg C, Weiland SK, von Mutius E, Abecasis GR, Farrall M, Gut IG, Lathrop GM, Cookson WO (2007) Genetic variants regulating ORMDL 3 expression contribute to the risk of childhood asthma. Nature 448:470-473

Moffatt MF, Gut IG, Demenais F, Strachan DP, Bouzigon E, Heath S, von Mutius E, Farrall M, Lathrop M, Cookson WO (2011) A large-scale, consortium-based genomewide association study of asthma. N Engl J Med 363:1211-1221

Mokrani H, Sharaf el Dein O, Mansuroglu Z, Bonnefoy E (2006) Binding of YY1 to the proximal region of the murine beta interferon promoter is essential to allow CBP recruitment and K8H4/K14H3 acetylation on the promoter region after virus infection. Mol Cell Biol 26:8551-8561

Murphy A, Chu JH, Xu M, Carey VJ, Lazarus R, Liu A, Szefler SJ, Strunk R, Demuth K, Castro M, Hansel NN, Diette GB, Vonakis BM, Adkinson NF Jr, Klanderman BJ, Senter-Sylvia J, Ziniti J, Lange C, Pastinen T, Raby BA (2010) Mapping of numerous disease-associated expression polymorphisms in primary peripheral blood CD4+ lymphocytes. Hum Mol Genet 19:4745-4757

Myers RM, Stamatoyannopoulos J, Snyder M, Dunham I, Hardison RC, Bernstein BE, Gingeras TR, Kent WJ, Birney E, Wold B, Crawford GE (2011) A user's guide to the encyclopedia of DNA elements (ENCODE). PLoS Biol 9:e1001046

Ogryzko VV, Schiltz RL, Russanova V, Howard BH, Nakatani Y (1996) The transcriptional coactivators p300 and CBP are histone acetyltransferases. Cell 87:953-959

Pastinen T, Sladek R, Gurd S, Sammak A, Ge B, Lepage P, Lavergne K, Villeneuve A, Gaudin T, Brandstrom H, Beck A, Verner A, Kingsley J, Harmsen E, Labuda D, Morgan K, Vohl MC, Naumova AK, Sinnett D, Hudson TJ (2004) A survey of genetic and epigenetic variation affecting human gene expression. Physiol Genomics 16:184-193

Raney BJ, Cline MS, Rosenbloom KR, Dreszer TR, Learned K, Barber GP, Meyer LR, Sloan CA, Malladi VS, Roskin KM, Suh BB, Hinrichs AS, Clawson H, Zweig AS, Kirkup V, Fujita PA, Rhead B, Smith KE, Pohl A, Kuhn RM, Karolchik D, Haussler D, Kent WJ (2011) ENCODE whole-genome data in the UCSC genome browser (2011 update). Nucleic Acids Res 39:D871-D875

Redgrove KA, Anderson AL, Dun MD, McLaughlin EA, O’Bryan MK, Aitken RJ, Nixon B (2011) Involvement of multimeric protein complexes in mediating the capacitation-dependent binding of human spermatozoa to homologous zonae pellucidae. Dev Biol 356:460-474

Saferali A, Grundberg E, Berlivet S, Beauchemin H, Morcos L, Polychronakos C, Pastinen T, Graham J, McNeney B, Naumova AK (2010) Cell culture-induced aberrant methylation of the imprinted IG DMR in human lymphoblastoid cell lines. Epigenetics 5:5060

Stahl EA, Raychaudhuri S, Remmers EF, Xie G, Eyre S, Thomson BP, Li Y, Kurreeman FA, Zhernakova A, Hinks A, Guiducci C, Chen R, Alfredsson L, Amos CI, Ardlie KG, Barton A, Bowes J, Brouwer E, Burtt NP, Catanese JJ, Coblyn J, Coenen MJ, Costenbader KH, Criswell LA, Crusius JB, Cui J, de Bakker PI, De Jager PL, 
Ding B, Emery P, Flynn E, Harrison P, Hocking LJ, Huizinga TW, Kastner DL, Ke X, Lee AT, Liu X, Martin P, Morgan AW, Padyukov L, Posthumus MD, Radstake TR, Reid DM, Seielstad M, Seldin MF, Shadick NA, Steer S, Tak PP, Thomson W, van der Helm-van Mil AH, van der Horst-Bruinsma IE, van der Schoot CE, van Riel PL, Weinblatt ME, Wilson AG, Wolbink GJ, Wordsworth BP, Wijmenga C, Karlson EW, Toes RE, de Vries N, Begovich AB, Worthington J, Siminovitch KA, Gregersen PK, Klareskog L, Plenge RM (2010) Genome-wide association study meta-analysis identifies seven new rheumatoid arthritis risk loci. Nat Genet 42:508-514

Verlaan DJ, Berlivet S, Hunninghake GM, Madore AM, Lariviere M, Moussette S, Grundberg E, Kwan T, Ouimet M, Ge B, Hoberman
R, Swiatek M, Dias J, Lam KC, Koka V, Harmsen E, Soto-Quiros M, Avila L, Celedon JC, Weiss ST, Dewar K, Sinnett D, Laprise C, Raby BA, Pastinen T, Naumova AK (2009a) Allele-specific chromatin remodeling in the ZPBP2/GSDMB/ORMDL3 locus associated with the risk of asthma and autoimmune disease. Am J Hum Genet 85:377-393

Verlaan DJ, Ge B, Grundberg E, Hoberman R, Lam KC, Koka V, Dias J, Gurd S, Martin NW, Mallmin H, Nilsson O, Harmsen E, Dewar K, Kwan T, Pastinen T (2009b) Targeted screening of cis-regulatory variation in human haplotypes. Genome Res 19:118-127

Yan H, Yuan W, Velculescu VE, Vogelstein B, Kinzler KW (2002) Allelic variation in human gene expression. Science 297:1143 